\title{
El surgimiento de un territorio circulatorio en la frontera chileno-peruana: estudio de las prácticas socio-espaciales fronterizas ${ }^{1}$
}

\author{
Marcela Tapia Ladino², Nanette Liberona Concha ${ }^{3}$ \\ y Yasna Contreras Gatica ${ }^{4}$
}

\begin{abstract}
RESUMEN
Este trabajo corresponde a los resultados de una encuesta aplicada en el paso fronterizo de Chacalluta, ubicado en el límite norte de Chile con Perú. A partir de esta información, datos de la Policía de Investigaciones y fuentes secundarias postulamos que, a pesar del carácter separador de la frontera chileno-peruana, las prácticas socio-espaciales fronterizas de chilenos y peruanos que cruzan y habitan la frontera entre Tacna y Arica producen un "territorio circulatorio" que da lugar a una continuidad transfronteriza a nivel territorial. A partir de los resultados de la encuesta se presentará el perfil de los cruzadores, los motivos, los tipos y formas de cruce, así como la descripción de las movilidades y prácticas socio-espaciales productivas y reproductivas encontradas, con el fin de visualizar el surgimiento del territorio circulatorio producto de las diversidad de movilidades.
\end{abstract}

Palabras clave: Frontera, movilidad, circulación, migración, prácticas socio-espaciales.

\begin{abstract}
This article presents the results of a survey conducted at the Chacalluta border crossing on Chile's northern border with Peru. Based on the survey, data collected by the police, and secondary sources, we postulate that although the Chile-Peru border separates the two countries, the socio-spatial border practices of the Chileans and Peruvians who cross and inhabit the border between Tacna and Arica produce a circulatory territory that generates cross-border continuity at the territorial level. Drawing on the survey results, we examine the profiles of these border crossers, their motivations, and the ways that they cross and provide a description of the socio-spatial productive and reproductive practices identified. All of this allows us to visualize the emergence of a circulatory territory as a result of the diversity of mobilities.
\end{abstract}

Key words: Border, mobility, circulation, migration, socio-spatial practices.

Este artículo es resultado del Proyecto FONDECYT Regular № 1150123. Queremos agradecer al equipo de investigación que trabajó en la elaboración, aplicación y explotación de la encuesta en especial a las ayudantes de investigación Damary Vilca, Fernanda Chacón e Isidora Palma. Asimismo agradecer a la Dra. Marina Ariza que asesoró el proceso de confección y explotación de la encuesta y cuya estancia en Chile se enmarcó en la Cooperación Internacional de este proyecto. Artículo recibido el 22 de febrero de 2016, aceptado el 5 de diciembre de 2016 y corregido el 20 de enero de 2017.

Instituto de Estudios Internacionales -INTE-, Universidad Arturo Prat (Chile). E-mail: marcela.tapia@unap.cl

Instituto de Estudios Internacionales -INTE-, Universidad Arturo Prat (Chile). E-mail: nalibero@unap.cl

Departamento de Geografía, Universidad de Chile (Chile). E-mail: ycontrerasg@uchilefau.cl 
La configuración de la frontera entre Chile y Perú data de fines del siglo XIX (1883) y con el Tratado de Lima se determinó el límite del territorio en litigio resultante de la Guerra del Pacífico y el destino de las ciudades de Tacna y Arica. Esta delimitación marcó un hito para las poblaciones locales, que pasaron a ser extranjeros, para luego ser chilenizadas y peruanizadas respectivamente a través de un proceso para-estatal y estatal que se destacó, en algunos momentos por la violencia (González, 2004, 2008). Desde fines del siglo XX y entrado el siglo XXI este espacio ha vuelto a la controversia por demandas limítrofes de parte del Perú, lo que ha avivado el carácter separador de la frontera. A pesar de la situación bilateral, el paso fronterizo de Chacalluta es el más transitado de Chile concentrando entre los años 2011-2014 en torno al 50\% del total de entradas y salidas terrestres con valores por sobre los 5 y 6 millones de cruces anuales en los últimos años según datos de la Policía de Investigaciones de Chile ${ }^{5}$. Así, la frontera ariqueña es además la principal puerta de entrada de los extranjeros que ingresan a Chile vía terrestre en el contexto de aumento de la inmigración sudamericana hacia Chile (Organización Internacional para las Migraciones, 2013) y es, al mismo tiempo, una zona de intensos movimientos de población chilena entre Arica y Tacna en las últimas décadas. Dentro de este contexto histórico nos situamos para iniciar una investigación sobre cómo se vive hoy en día en esta frontera y, en particular, cómo las poblaciones de ambas ciudades se relacionan con ella mediante el cruce. La particularidad de Tacna y Arica es que ambas ciudades son capitales de sus unidades administrativas y tienen en común que están alejadas de los centros políticos de sus respectivos países. La primera en $1.310 \mathrm{~km}$. respecto de Lima y la segunda en más de $2000 \mathrm{~km}$. respecto de Santiago. Sin embargo la distancia entre ambas ciudades no supera los $60 \mathrm{~km}$. y el tiempo de traslado, en la actualidad es de una hora y media aproximadamente. Desde el punto de vista demográfico el departamento de Tacna cuenta con una población de 324.498 habitantes según datos del Instituto Nacional de Estadísticas e Informática (INEI) de 2011, lo que representa el 1,1\% de la población peruana total. En el caso de la Región de Arica y Parinacota, posee una población proyectada para el 2015 es de 239.126 mil habitantes lo que representa el 1,3\% de la población nacional (INE, s/f).

La amplia producción sobre migración en Chile se ha preocupado de los migrantes establecidos en Chile y los vínculos que crean con el país de origen (Luque, 2007; Solimano et al., 2012; Stefoni, 2009; Stefoni y Fernández, 2011; Stefoni, 2011), centrando la atención en lo que ocurre en Santiago como "epicentro de lo nacional" (Grimson y Lube-Guizardi, 2015: 21). Estos recortes de la realidad se han detenido menos en el análisis que vincula los fenómenos que ocurren en las regiones fronterizas ${ }^{6}$ y que escapan al estrecho margen de la noción de migración. Nos referimos a la movilidad fronteriza que no siempre tiene como propósito el establecimiento sino fines diversos (económicos y sociales), distintas modalidades (formal e informal) y temporalidades (idas y venidas, circulación, temporadas, etc.). Asimismo estos estudios no han dado cuenta del movimiento inverso de población, es decir, de chilenos que cruzan la frontera sin el afán de instalarse en el país de destino, sino para aprovechar las ventajas de los cruces fronterizos. En general, las Ciencias Sociales no han mirado los movimientos de población chileno hacia Perú, su tipificación

\footnotetext{
Información obtenida de la Sección de Acceso de Información Pública de la Policía de Investigación por la Ley de Transparencia N²0.285 con fecha 29/09/15

6 En los últimos años han aumentado los estudios, libros, artículos y tesis, que vinculan frontera y movilidad humana. Cabe una mención especial al libro recientemente publicado por Menara Lube-Guizardi y del Servicio Jesuita Migrante que apunta en esta dirección (Lube-Guizardi, 2015; Vicuña y Rojas, 2015)
} 
y caracterización, sino por el contrario se han centrado en la inmigración de sudamericanos hacia Chile, su establecimiento y consecuencias de su llegada. En ambos casos se aprecia un desconocimiento de la movilidad fronteriza, del impacto que tienen los cruces en ambos sentidos y de la territorialización que producen las prácticas fronterizas, especialmente llamativo cuando se trata de una región que remite constantemente al carácter histórico de su configuración y donde, de cuando en cuando, se reaviva el carácter divisor del límite.

En este escenario nos interesa indagar por los movimientos de población de los residentes de Tacna y Arica con el objetivo de dilucidar y analizar las prácticas socio-espaciales fronterizas que dan por resultado movilidades de chilenos y peruanos que cruzan por el paso de Chacalluta y los factores que propician el surgimiento de un "territorio circulatorio" (Tarrius, 2000, 2007). Esta noción, según Tarrius (2010) "da cuenta de la socialización de espacios que sirven de soporte a las prácticas de movilidad e introduce una doble ruptura en las concepciones comunes del territorio y de la circulación. En primer lugar, nos sugiere que el orden nacido de la sedentarización no es esencial para la manifestación del territorio; en segundo lugar para otorgar sentido social al movimiento espacial, exige una ruptura con los conceptos logísticos de las circulaciones, de los flujos" (Tarrius, 2010: 139). Para captar la movilidad que da lugar a este territorio circulatorio diseñamos una encuesta que se aplicó a residentes de Arica y/o Tacna, que tenían como destino al momento del cruce, una de esas ciudades.

El manuscrito se organiza de la siguiente forma, en la primera parte establecemos el marco teórico que guía el análisis, en particular una revisión sucinta de la producción sobre frontera y migración desde la perspectiva de la circulación humana fronteriza. Luego nos detenemos en el crecimiento y magnitud del cruce por el paso fronterizo en los últimos años para lo cual explotamos datos entregamos por la Policía de Investigaciones de Chile (PDI) y la importancia de aplicar una encuesta en dicho lugar. La tercera corresponde a la explotación de los datos obtenidos por la encuesta, la tipificación de las movilidades encontradas y las prácticas sociales fronterizas productivas y reproductivas asociadas a los cruces. Para finalizar desarrollamos las conclusiones de acuerdo al marco teórico utilizado y los aportes de la investigación al conocimiento de la circulación fronteriza.

\section{Los estudios de frontera y migración para el análisis de la circulación humana fronteriza}

Los estudios de frontera han experimentado cambios en las últimas décadas pasando de la preocupación por el límite y su carácter contenedor en clave geopolítica, a una mayor atención por la interacción y los vínculos que ocurren a través de ellas y que despliegan las personas en sus constantes cruces (Morales, 2010; Parella, 2014). En los últimos 20 años en América Latina se ha manifestado una mayor preocupación por las fronteras en el marco de los procesos de integración en Europa y del MERCOSUR. Este hecho ha llamado la atención por parte de los cientistas sociales interesados en rescatar la dimensión sociocultural de las fronteras con el afán de evitar reducir la integración a aspectos netamente económicos (Jaquet, 2008; Liberona, 2015). Así el debate latinoamericano ha transitado de la noción de la frontera como marginal y secundaria a la idea de la frontera como centro donde hay interés por los intercambios socioculturales (Dilla, 
2008; Jaquet, 2008). Éstos últimos se agrupan en dos grandes cuerpos de interpretación, por una lado el interés por los "efectos materiales y simbólicos que implicó la fijación de los límites" en los Estados-nacionales y por otro, una mirada que atiende a los "muchos circuitos de intercambios, códigos e historias compartidas entre las poblaciones de ambos lados de las fronteras" (Jaquet, 2008: 35). Así se ha pasado de la preocupación por el trazado o demarcación a la atención por "las prácticas de (re)producción social de la frontera, en tanto el límite, la frontera y la movilidad devienen recursos, para definir estrategias de reproducción a partir del aprovechamiento de las disparidades entre territorios" (Benedetti y Salizzi, 2011: 151). Estas disparidades se traducen en prácticas que establecen las personas al cruzar las fronteras con distintos fines, especialmente de reproducción social, por tanto movilidad, frontera, contacto y control son términos relacionados (Benedetti y Salizzi, 2011: 153).

En un sentido similar los estudios migratorios han debatido en el último tiempo sobre el modelo de migrar, tanto por los supuestos del nacionalismo-metodológico contenidos en su definición como por la estrechez de la definición que no da cuenta suficientemente de la variedad de movimientos y sus motivos (Cruz y Quintero, 2011; Heyman, 2012; Mallimaci, 2012). Por una parte se presume que el movimiento de población es excepcional, que separa a dos espacios geográficos determinados y que es un medio para satisfacer objetivos que se alcanzan en el país de destino (Mallimaci, 2012: 78). En este sentido, los estudios de retorno en México (Durand, 2006; Fimbres, 2000), España (Cavalcanti y Parella, 2013) y Bolivia (Hinojosa, 2000) han advertido de la necesidad de considerar el regreso como una etapa más de la migración y "como patrones de circularidad sustentados en "dobles" o múltiples identidades y formas de pertenencia que no están ancladas ni en el lugar de origen ni en el de destino" (Parella, 2013: 23). Es decir, como un recurso al que se recurre ante crisis económica, deudas o para satisfacer necesidades puntuales en el marco del ciclo de vida familiar (Cortés, 2009; Tapia y Ramos, 2013). Por tanto, el retorno y la circulación se configuran como parte de los proyectos migratorios que al mismo tiempo se constituyen en capital o en un "saber migrar" (Tapia y Parella, 2015).

Hasta hace poco tiempo los estudios migratorios utilizaron distintas acepciones para denominar a las migraciones de corta duración, entre ellos migración temporal o pendular, sin hacer mayores distinciones en las particularidades de estos movimientos más allá de la temporalidad (Cavalcanti y Parella, 2013). Sin embargo la crisis reciente en Europa mediterránea y la existencia de un contexto favorecedor de la movilidad en el espacio Schengen muestran un aumento de este tipo de movimientos de población (Marcu, 2013). En un sentido similar, las regiones fronterizas llevan mucho tiempo siendo escenario de movimientos constantes de población que cruza con fines laborales y que aprovecha los ciclos agrícolas o el efecto llamada de los mercados de trabajo fronterizos. Dichos espacios se constituyen en regiones que "polarizan" los flujos de ingreso, salida y tránsito de personas (Cortés, 2009: 37). Por tanto, como fenómeno no son del todo nuevos, sin embargo existe poca discusión teórico-conceptual sobre esos movimientos particulares, pero que tienen su correlato en distintas partes del mundo, por lo que surge la necesidad de precisar las especificidades de la movilidad en esos territorios.

En este sentido la academia francesa, con Alain Tarrius, aportó la noción de paradigma de la movilidad en el marco de la antropología del movimiento, en sus estudios sobre el comercio entre Marsella, Argelia y Marruecos (Tarrius, 2007). A partir de investigaciones realizadas desde la década de 1980, Tarrius detectó nuevas formas de migrar y circular en Europa por comerciantes y redes económicas subterráneas que conectaban el Magreb con la costa mediterránea (2001). 
Esto le permitió relativizar la noción de migración y utilizar la noción de circulación que tiene la ventaja de tomar en cuenta las diversas formas de migrar, las idas y vueltas, y el "carácter circular de los itinerarios" (Cortés, 2009). En un contexto de mayores intercambios se observa un aumento y densificación de las redes internacionales y de la circulación de bienes y servicios que invitan a mirar los distintos tipos de movimientos que no implican el asentamiento en el "destino". Así, este autor distingue tipos de sujetos móviles que son capaces de estar aquí y allá diferenciados por sus relaciones con la sociedad y lugar de origen y las relaciones que establecen en sus trayectorias. Vagancia, diásporas y nomadismos son algunas de las acepciones acuñadas por Tarrius para aludir a tipos de personas que mantienen fuertes vínculos con su sociedad de origen, pero que describen una centralidad con los territorios durante los trayectos que realizan. En algunos casos, como los nómades, establecen una "complementariedad morfológica" con la sociedad que los acoge sin perder la fidelidad con su origen, un ejemplo de ellos son los comerciantes. Por ejemplo acuña la noción de nomadismo que "se caracteriza, según nuestros tres criterios, por la fidelidad a un lugar de origen, por la ausencia de especialización profesional heredada y por una postura de distanciamiento respecto de las perspectivas de integración; $y$, a veces, por la instrumentalización pasajera de la ciudadanía" (Tarrius, 2007: 50).

En el mismo sentido y siguiendo los aportes de Tarrius, la Escuela de Poitiers en Francia discutió en los años 90 la idea de evento-ruptura contenido en la migración para mirar "las construcciones sociales que surgen en el proceso migratorio" (Cortés, 2009: 37). Los estudios migratorios estaban dando cuenta de una cierta incomodidad con la noción de migración porque impedía captar movimientos de población que no tenían por objetivo la residencia en un sitio o que no quedaban suficientemente reflejados en la migración circular. Como señala Cortés estas modalidades pasaban a formar una "categoría residual" de la migración de escaso interés para los estudios migratorios porque los sujetos no estaban asentados en el país de destino (Cortes, 2009). Como señalamos en otro trabajo (Tapia y Parella, 2015) el debate sobre migración converge con las críticas hechas al transnacionalismo migrante en tanto el campo social transnacional no se da en el aire sino que está situado y anclado a uno o más territorios. "El transnacionalismo emana de un territorio nacional y de ahí se extiende a uno o más países" (Sinatti, 2008: 97). Evidentemente el aporte del nacionalismo-metodológico permitió atender a las prácticas que los migrantes desarrollan para mantener los vínculos de uno y otro territorio, pero siempre desde un lugar.

Así el estudio de los movimientos de población en regiones fronterizas es el lugar propicio para captar dicha variedad y desafía a operacionalizar los distintos flujos para mirarlos desde el territorio. Del debate sobre migración surgió un concepto más amplio e inclusivo, el de movilidad, concepto que hace "menos juicios acerca de la naturaleza del movimiento (duración, propósito, posición social)" (Heyman, 2012: 428). Entre los elementos definitorios de la noción de movilidad se encuentran el espacio, el tiempo y los motivos (Castillo y Nájera, 2014). La migración implica regularmente un cambio de residencia habitual de un lugar de origen a otro de destino, y en ocasiones de tránsito. En cambio la movilidad incluye ambos espacios, pero sin cambio de residencia porque los movimientos son de corta duración, de algunos días o de menos de una semana. Por otro lado, el motivo o propósito define el tipo de movilidad, por ejemplo si es por motivos laborales, como es el caso de los commuters, acepción que se utiliza para denominar "a las personas que viven en un país y que cruzan a trabajar a otro" (Castillo y Nájera, 2014: 19) o para designar a las personas que cruzan la frontera (en ambos sentidos) con cualquier fin específico: trabajar, estudiar, visitar familiares, ir de turismo y de compras o quienes se mueven entre dos localidades en un mismo país (Chavez, 2016). En este sentido el concepto permite adjetivizar otros movimientos 
como el de movilidad turística, de compras, gastronómica o de ocio para aludir a las personas que cruzan las fronteras para realizar cualquiera de estas actividades, pero que no cambian de residencia. Las brechas de desarrollo y las asimetrías que contienen las fronteras, permiten convertir su cruce en un recurso y en una posibilidad visto desde las estrategias individuales o familiares (Sassone, 2010: 251).

\section{Aplicación de una encuesta en Chacalluta para captar la movilidad}

El marco jurídico sobre ingreso y tránsito de personas por la frontera norte de Chile explica, en parte el flujo de población por ese paso fronterizo. El año 1983 se firmó el "Convenio de tránsito de personas en la zona fronteriza chileno-peruana de Arica y Tacna" que permitió el cruce de la frontera con salvoconducto y luego, gracias al "Acuerdo para el ingreso y tránsito de nacionales peruanos y chilenos en calidad de turistas con documento de identidad" del año 2005, fue posible cruzar con DNI en el caso de los peruanos y carnet de identidad para los chilenos ${ }^{7}$. Este acuerdo permitía el cruce sólo por 7 días para realizar actividades turísticas en las ciudades de Arica y Tacna respectivamente, e impedía trabajar o realizar actividades con fines de lucro. Sin embargo investigaciones recientes muestran que esto es válido en el caso de los chilenos, que van a Tacna con fines turísticos, comerciales y de ocio, entre otros (Lube et al., 2013; Tapia, 2014). Pero no es el caso de los peruanos, que llegan a Arica con fines fundamentalmente laborales y comerciales.

Respecto del paso fronterizo podemos señalar que el Complejo fronterizo de Chacalluta está ubicado en la comuna de Arica, distante $12,9 \mathrm{~km}$ al norte de la ciudad y a $50 \mathrm{~km}$ de la ciudad de Tacna en Perú. Es un paso permanente que funciona las 24 horas del día y posee una ruta pavimentada transitable. Al otro lado de la frontera, en el lado peruano se encuentra el Control fronterizo Santa Rosa a menos de un kilómetro de distancia (Figura $N^{\circ} 1$ ). No existen vínculos administrativos entre ambos controles, como en otros casos, por tanto quienes cruzan deben controlarse en los dos complejos, extendiendo de esta manera la duración del cruce ${ }^{8}$. En su seno interactúan varias instituciones; en Chacalluta a la salida de Chile se realiza el control migratorio y de vehículos por parte de la PDI y al ingreso a Chile se suma el control de Aduanas y Servicio Agrícola y Ganadero (SAG).

Como señalan distintos estudios e informes sobre migraciones en Chile entrado el siglo XXI se registra no sólo un aumento de la migración sino una aceleración de su crecimiento. Según la actualización de cifras demográficas del Instituto Nacional de Estadísticas INE, la migración hacia Chile creció un 160\% entre el año 2002 y 2012 (Matus, 21 de septiembre de 2014). En este mismo sentido las estimaciones del Departamento de Extranjería y Migraciones DEM del Ministerio del Interior y Seguridad Pública, señalan que para el año 2014 los extranjeros en Chile ascendían a 410.988 personas, muy lejos de los 184.464 del año 2002, lo que representa un crecimiento de

Desde el año 2013 y por acuerdo de las autoridades migratorias se ha dejado de aplicar el primero de estos, conocido como "Convenio de Arica y Tacna". En la actualidad los peruanos que ingresan a Chile lo pueden hacer con DNI hasta por 90 días a cualquier lugar de Chile y los chilenos pueden ingresar por 90 días a cualquier lugar del Perú.

Nos referimos a los vínculos que existen por ejemplo en el Control integrado de cabecera única Chile-Bolivia paso Visviri-Charaña, el de Colchane-Pisiga y el Control integrado de doble cabecera Chile-Argentina, Paso los Libertadores -Horcones, entre otros, que permiten un control más expedito y rápido. 
Figura $\mathrm{N}^{\circ} 1$

Paso fronterizo de Chacalluta

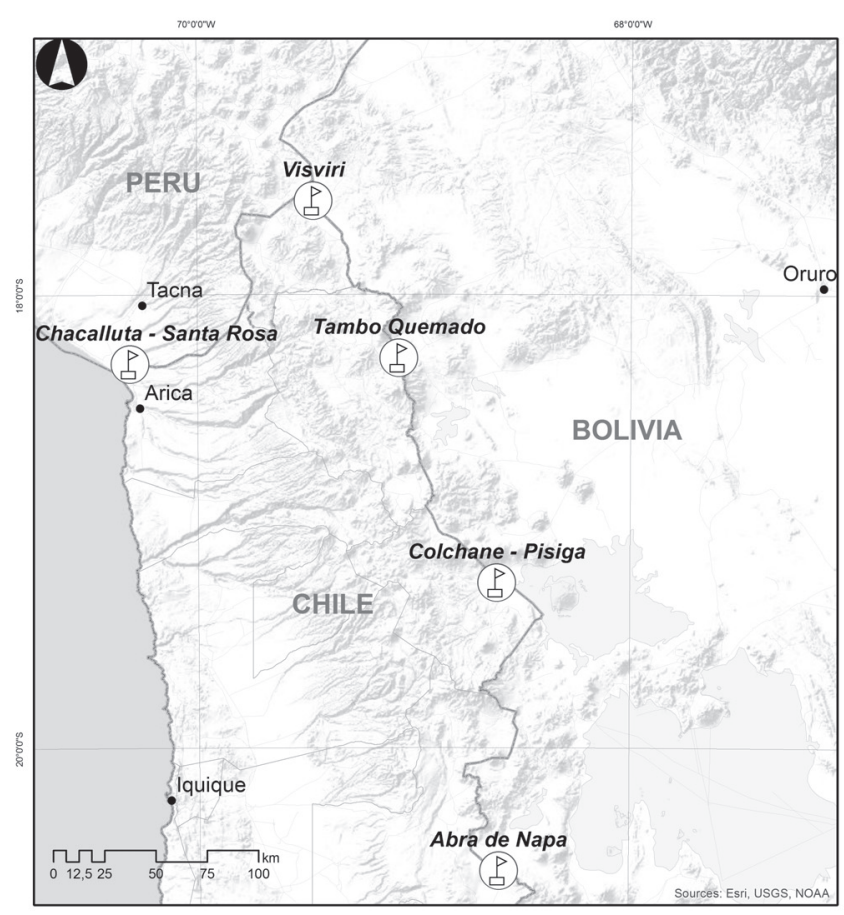

\section{PASOS FRONTERIZOS}

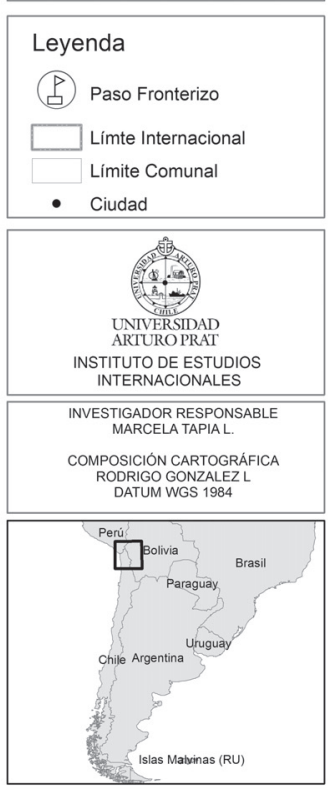

Fuente: Elaboración propia.

$123 \%$ respecto de dicho censo y un $2,7 \%$ de la población total (http://www.extranjeria.gob.cl//) Por tanto el complejo fronterizo de Chacalluta, presenta un alto flujo de personas, quintuplicando el número de cruces desde el año 2000 al 2014 con más de 6 millones de entradas y salidas el año 2016 según lo informado por la PDI.

Cuadro $\mathrm{N}^{\circ} 1$

Total de entradas y salidas por el paso fronterizo de Chacalluta 2000-2014

\begin{tabular}{|l|r|r|r|}
\hline AÑO & Total Entradas & Total Salidas & \multicolumn{2}{|c|}{ Total } \\
\hline 2000 & 588.925 & 576.447 & 1.165 .372 \\
\hline 2001 & 504.582 & 497.074 & 1.001 .656 \\
\hline 2002 & 493.013 & 502.864 & 995.877 \\
\hline
\end{tabular}

9 En el mismo sentido y según datos de la Organización Internacional para las Migraciones (OIM) de Perú después del aeropuerto Internacional Jorge Chávez, que aglutina el 41,5\% del total de peruanos emigrados, le sigue el puesto de control fronterizo de Santa Rosa con el $30 \%$ del total de salidas para el periodo 1990-2012. Según esta misma fuente el número de peruanos en el exterior alcanzó la cifra de "2 millones 572 mil 532 peruanos que registraron su salida y no han retornado al país" (OIM, 2013: 15). 
Continuación Cuadro $N^{\circ} 1$

\begin{tabular}{|l|r|r|r|}
\hline AÑO & Total Entradas & Total Salidas & \multicolumn{1}{|c|}{ Total } \\
\hline 2003 & 563.762 & 558.328 & 1.122 .090 \\
\hline 2004 & 720.349 & 706.396 & 1.426 .745 \\
\hline 2005 & 892.909 & 917.834 & 1.810 .743 \\
\hline 2006 & 1.099 .073 & 1.093 .975 & 2.193 .048 \\
\hline 2008 & 2.027 .358 & 2.011 .067 & 4.038 .425 \\
\hline 2009 & 2.099 .340 & 2.097 .399 & 4.196 .739 \\
\hline 2010 & 2.279 .085 & 2.258 .744 & 4.537 .829 \\
\hline 2011 & 2.513 .693 & 2.509 .125 & 5.022 .818 \\
\hline 2012 & 2.522 .267 & 2.566 .416 & 5.088 .683 \\
\hline 2013 & 2.814 .513 & 2.806 .603 & 5.621 .116 \\
\hline 2014 & 2.846 .277 & 2.840 .850 & 5.687 .127 \\
\hline Total general & 21.965 .146 & 21.943 .122 & 43.908 .268 \\
\hline
\end{tabular}

Fuente: Elaboración propia basado en datos de PDI Transparente.

Al revisar el lugar que ocupa la Región de Arica y Parinacota por ingreso terrestre respecto de las demás regiones comprobamos que ésta concentra casi el $50 \%$ del total de ingresos y salidas terrestres a nivel nacional en los últimos años ${ }^{10}$ (Cuadro $N^{\circ} 2$ ). Asimismo, dentro de la Región de Arica-Parinacota, el paso terrestre de Chacalluta concentra casi el 90\% del total de cruces de la región constituyéndose a su vez en la avanzada más transitada del país.

Cuadro $\mathrm{N}^{\circ} 2$

Distribución de las entradas y salidas terrestres por año y región. 2011 -2014

\begin{tabular}{|l|r|r|r|r|r|r|r|r|}
\hline $\begin{array}{l}\text { Pasos } \\
\text { terrestres }\end{array}$ & \multicolumn{2}{|c|}{2011} & \multicolumn{2}{|c|}{2012} & \multicolumn{2}{|c|}{2013} & \multicolumn{2}{|c|}{2014} \\
\hline Región & Entradas & Salidas & Entradas & Salidas & Entradas & Salidas & Entradas & Salidas \\
\hline $\begin{array}{l}\text { Arica y } \\
\text { Parinacota }\end{array}$ & 2.801 .426 & 2.776 .465 & 2.814 .367 & 2.805 .065 & 3.097 .786 & 3.073 .471 & 3.126 .921 & 3.096 .686 \\
\hline Tarapacá & 168.365 & 151.080 & 233.555 & 214.631 & 0 & 0 & 301.554 & 273.069 \\
\hline Antofagasta & 117.377 & 135.458 & 137.501 & 139.932 & 150.037 & 141.172 & 168.766 & 163.115 \\
\hline Atacama & 4.377 & 7.643 & 7.770 & 4.811 & 7.921 & 4.984 & 4.956 & 4.971 \\
\hline Coquimbo & 16.007 & 13.456 & 21.475 & 18.668 & 17.373 & 16.593 & 18.204 & 16.608 \\
\hline Valparaíso & 933.583 & 910.797 & 1.013 .782 & 996.948 & 892.976 & 841.905 & 935.817 & 908.827 \\
\hline Metropolitana & 0 & 0 & 0 & 0 & 18 & 0 & 285 & 25 \\
\hline Maule & 391 & 731 & 1.561 & 1.482 & 19.653 & 24.269 & 17.805 & 18.065 \\
\hline
\end{tabular}

10 El aeropuerto de Santiago es el que registra los mayores ingresos y salidas aéreas a nivel nacional con 5.219.792 el año 2011, 5.908.097 el año 2012, 6.287.436 el año 2013 y 6.459.953 el año 2014. Sin embargo este año 2017 se concretará el control integrado entre los controles de Santa Rosa y Chacalluta. 
Continuación Cuadro $N^{\circ} 2$

\begin{tabular}{|l|r|r|r|r|r|r|r|r|}
\hline $\begin{array}{l}\text { Pasos } \\
\text { terrestres }\end{array}$ & \multicolumn{2}{|c|}{2011} & \multicolumn{2}{|c|}{2012} & \multicolumn{2}{|c|}{2013} & \multicolumn{2}{|c|}{2014} \\
\hline Región & Entradas & Salidas & Entradas & \multicolumn{1}{|c|}{ Salidas } & Entradas & Salidas & Entradas & Salidas \\
\hline Biobío & 1.156 & 1.220 & 1.944 & 1.959 & 1.878 & 2.126 & 2.060 & 2.169 \\
\hline $\begin{array}{l}\text { La } \\
\text { Araucanía }\end{array}$ & 274.699 & 276.176 & 316.855 & 317.923 & 350.389 & 351.760 & 349.032 & 349.430 \\
\hline Los Ríos & 0 & 0 & 0 & 0 & 0 & 0 & 58 & 60 \\
\hline Los Lagos & 390.567 & 398.102 & 476.226 & 486.095 & 495.978 & 503.176 & 540.720 & 93.510 \\
\hline Aysén & 130.468 & 134.373 & 143.952 & 146.531 & 156.196 & 139.164 & 157.779 & 163.037 \\
\hline Magallanes & 867.544 & 854.161 & 933.368 & 907.349 & 979.540 & 971.028 & 930.076 & 919.728 \\
\hline Total & 5.705 .960 & 5.659 .662 & 6.102 .356 & 6.041 .394 & 6.169 .745 & 6.069 .648 & 6.554 .033 & 6.009 .300 \\
\hline
\end{tabular}

Fuente: Elaboración propia basado en datos de PDI Transparente.

Si bien los datos revisados dan cuenta la magnitud de los cruces por el paso fronterizo de Chacalluta la fuente sólo releva el número de entradas y salidas y en algunos años (2000-2010) por nacionalidad y estatus jurídico con el que cruzan (residentes, turistas y convenio). Asimismo los datos se refieren al total de ingresos y egresos, pero no necesariamente se corresponde con las personas, puesto que hay casos como los de taxistas, choferes y comerciantes que cruzan en más de una ocasión durante el día. Sin embargo, más allá de los datos que entrega la PDI, no contamos con la aplicación de una encuesta en la frontera que capte los motivos que tienen las personas para cruzarla, su destino o la temporalidad de sus estadías.

En América Latina, México es un ejemplo de aplicación de una encuesta en la frontera, se trata de la Encuesta sobre Migración en la Frontera Norte de México (Emif Norte) que se aplica desde el año 1993 y cuyo objetivo es "profundizar en el conocimiento del fenómeno migratorio laboral a la frontera norte de México y Estados Unidos, destacando su naturaleza, volumen, y tendencias, así como sus efectos en el mercado de trabajo e impactos en ambas sociedades" (Castillo y Nájera, 2014: 19). Esta encuesta se realiza en las localidades de mayor intensidad migratoria en la frontera de México-Estados Unidos y la aplican varias instituciones. La Emif capta cuatro flujos migratorios de acuerdo con la dirección de su movimiento: migrantes procedentes de Estados Unidos, mexicanos 'indocumentados' devueltos por la 'patrulla fronteriza', mexicanos procedentes de la Frontera Norte y mexicanos procedentes del sur con la intención de trabajar en el Norte o de cruzar a Estados Unidos. Se realiza en lugares donde se concentran los migrantes que están en movimiento y permite obtener información permanentemente actualizada (Castillo y Nájera, 2014). Si bien nuestra intención no es captar sólo el fenómeno migratorio laboral, sí nos interesa conocer los flujos de población y distinguir las diversas movilidades que ocurren en esta frontera. En este sentido, consideramos que la aplicación de una encuesta en la frontera entre Arica y Tacna es fundamental para develar la incidencia de las movilidades humanas en el surgimiento de un territorio circulatorio en un espacio transfronterizo.

Para nuestro caso se realizaron un total de 240 encuestas en el paso fronterizo chileno de Chacalluta entre el 17 y el 23 de julio de 2015, previa aplicación del piloto en el mes de junio lo 
que permitió ajustar el instrumento"11. La encuesta tenía un total de 54 preguntas, sin embargo los y las encuestados/as, luego de responder a un set de preguntas de tipo sociodemográfico, respondieron de acuerdo al motivo del cruce que declararon (turismo, trabajo, asunto personal, comercio, salud). Estas fueron categorías abiertas. Por ejemplo, si declaraban cruzar por "turismo", respondían una parte común para todos/as los y las encuestados, sobre frecuencia, tipo de transporte y si viajaban solos o acompañados, y luego respondían un set de preguntas dirigidas a un determinado perfil, en este caso "turista". Estos "perfiles" fueron preestablecidos como categorías cerradas, siendo: migrante, trabajador, comerciante o turista. Así cada encuestado respondió la encuesta de acuerdo a un perfil predefinido. Estas categorías son mutuamente excluyentes, considerando el tipo de movimiento declarado al momento de la encuesta.

La encuesta sólo se aplicó a personas mayores de 18 años residentes de Arica y Tacna y que tuvieran por destino a una de esas ciudades. Destacamos que la encuesta fue aplicada a "individuos" y no a grupos familiares. El diseño de la encuesta fue realizado por nuestro equipo, en función de la realidad local, basándonos para su confección en tres fuentes: Las encuestas Emif; Movilidad y Retorno, que se aplicó entre España y Marruecos y España y Bolivia y Programa PARMI de Argentina y en su análisis contó con asesoría internacional ${ }^{12}$. De cada una de ellas se tomaron preguntas que se ajustaron a los propósitos de nuestra investigación. El tiempo de aplicación varió entre 5 y 12 minutos y se aprovechó el tiempo de espera en la fila de ingreso o salida del complejo Chacalluta, es decir, sólo se aplicó en el lado chileno. Es importante señalar que este tiempo de espera es bastante significativa en ambos sentidos del cruce, debido al propio dinamismo de la circulación. La encuesta fue aplicada por las tres investigadoras del proyecto y dos ayudantes en los sectores de ingreso y salida de Chile y en franjas horarias que permitieran captar la variedad de cruces (mañana, mediodía y noche). El universo encuestado (240) estuvo compuesto por 147 peruanos, 91 chilenos, 1 ecuatoriano y 1 boliviana, de los cuales 121 son hombres y 119 mujeres, del total captamos 153 ingresos a Chile y 87 salidas del país.

\section{Movilidades y prácticas socio-espaciales fronterizas entre Arica y Tacna}

Como señalamos más arriba la encuesta aplicada buscó indagar por los movimientos de población chilena y peruana que tienen como referente a la frontera norte de Chile y sur de Perú y por las prácticas de índole económica, laboral, social y espacial que se construyen en torno al cruce fronterizo entre Tacna y Arica. Varios factores como la existencia del Convenio de Tacna y Arica ha favorecido el cruce de la frontera, así como las brechas de desarrollo de ambos países que se traducen en desigualdades regionales y diferencias cambiarias y la existencia de un mercado laboral regional que atrae mano de obra especialmente para la agricultura ariqueña (Tapia, 2014). Por tanto paradójicamente el límite lejos de separar favorece el intercambio entre sus habitantes lo que se traduce en prácticas sociales que tienen a la interacción con la frontera y al cruce como rasgo definitorio (Parella, 2014: 47).

Se escogió este número en función de la capacidad del equipo investigador de aplicar una encuesta en terreno. Por lo tanto, la muestra lograda no corresponde a una muestra aleatoria representativa en términos estadísticos de la población objetivo, sino que es representativa de una "pseudo-población", que se aproxima, pero no es idéntica (Wang et al., 2005).

12 Dentro del Proyecto FONDECYT 1150123 participó en Cooperación Internacional la Dra. Marina Ariza quien asesoró el proceso de confección de la encuesta y luego la explotación de los datos. 
De manera similar al estudio de Parella (2014) en el caso de Mexicali-Caléxico, entendemos por prácticas socio-espaciales fronterizas a las actividades que tienen o han tenido como referente la frontera y más propiamente la región fronteriza, entendida como espacio de "desarrollo de un conjunto de actividades al interior de cada estado y que tienen a la frontera como un centro vital de referencia" (Morales, 2010: 187). Se trata de prácticas socio-espaciales porque tienen una expresión en el territorio que se traducen en cruces y trayectorias en un espacio geográfico específico. Entre ellas distinguimos las prácticas productivas como "las estrategias para lograr empleo, beneficio económico o medios materiales para la subsistencia" (Parella, 2014:57) y las distintas estrategias para la obtención de ingresos o abaratamiento del costo de la vida. Por prácticas reproductivas entendemos las acciones "que tienen como fin asegurar la reproducción social, vivienda, acceso a servicios sociales (educación, salud y saneamiento, seguridad) y recreación" (Morales, 2010: 191). Estas prácticas no ocurren desconectadas de las estructuras económicas y políticas de los países incluidos en este estudio, es decir, en su condición binacional, sino que el foco fue su expresión en el territorio donde la "transfrontericidad", es decir, las conexiones e interacciones hacia uno y otro lado de la frontera es lo característico.

En particular, interesó observar los factores que incentivan dichas prácticas socio-espaciales, entre ellas, los procesos de diferenciación entre las dos ciudades y la complementariedad ${ }^{13}$ que se produce por esas diferencias. Por tanto, comprobar si la interacción transfronteriza que existe entre dos ciudades, separadas por un límite internacional, genera diferencias estructurales que permiten y son el motivo de la relación entre estos territorios (Alegría, 2000). Asimismo, interesó indagar por el lugar que ocupa la proximidad, es decir, la cercanía y la accesibilidad de ambos lugares como elemento multiplicador de las prácticas socio-espaciales.

\section{¿Quiénes cruzan la frontera de Arica- Tacna?}

En la primera parte de la encuesta, que respondieron todos los encuestados, se identificó el perfil de quienes cruzaban hacia Arica o hacia Tacna de acuerdo al perfil sociodemográfico y motivo del cruce (Cuadro $N^{\circ} 3$ ). En esta primera parte se identificaba el motivo del cruce y eso derivaba más tarde al set de preguntas por tipo de movilidad. Del total de encuestados, 147 (61.5\%) fueron peruanos, de los cuales 53 declararon cruzar por motivos de trabajo $(36,1 \%), 43$ declararon cruzar por motivos comerciales $(29,3 \%), 30$ por asuntos personales $(20,4 \%), 10$ porque trabajan en torno a la frontera, por lo que los clasificamos como in between ${ }^{14}(6,8 \%), 9$ por motivo de turismo general $(6,1 \%)$ y 2 por turismo de compra $(1,4 \%)$.

De los 91 encuestados de nacionalidad chilena, es decir el 38.1\% del total de la muestra, la mayoría, es decir, 36 personas cruzaron la frontera por turismo médico $(39,6 \%)$ y 33 por turismo general (36,3\%). Le siguen 10 personas que cruzaron por un asunto personal (11\%), 9 por turismo de compras $(9,9 \%), 2$ declararon cruzar por trabajo $(2,2 \%)$ y 1 por comercio $(1,1 \%)$. Del total de encuestados dos eran de otros países: un ecuatoriano que reside en Tacna y cruza por un Asunto personal y una mujer boliviana que reside en Arica, su motivo de viaje es turismo general.

Complementariedad fronteriza: Se refiere a la existencia de mercados de trabajo y oferta de productos que se completan o perfeccionan por el hecho de cruzar la frontera hacia Arica o hacia Tacna.

14 El concepto de in between se refiere a cuando los migrantes "experimentan su "ser en el medio"...esto puede ser entendido como una experiencia de frontera" (Gielis, 2009: 599). En este caso, se relaciona con las personas que trabajan en torno a la frontera. 


\section{Cuadro $\mathrm{N}^{\circ} 3$}

Motivos para cruzar la frontera de residentes de Arica y Tacna por nacionalidad

\begin{tabular}{|l|r|r|r|r|r|r|r|r|}
\hline \multirow{2}{*}{ Motivo del cruce } & \multicolumn{2}{|c|}{ Chilena } & \multicolumn{2}{c|}{ Peruana } & \multicolumn{2}{c|}{ Otra } & \multicolumn{2}{c|}{ Total } \\
\cline { 2 - 10 } & \multicolumn{1}{c|}{$\mathrm{n}^{\circ}$} & \multicolumn{1}{c|}{$\%$} & \multicolumn{1}{c|}{$\mathrm{n}^{\circ}$} & \multicolumn{1}{c|}{$\%$} & \multicolumn{1}{c|}{$\mathrm{n}^{\circ}$} & \multicolumn{1}{c|}{$\%$} & $\mathrm{n}^{\circ}$ & \multicolumn{1}{c|}{$\%$} \\
\hline Turismo médico & 36 & 39,6 & 0 & 0,0 & 0 & 0,0 & 36 & 15,0 \\
\hline Turismo general & 33 & 36,3 & 9 & 6,1 & 1 & 50,0 & 43 & 17,9 \\
\hline Turismo de compra & 9 & 9,9 & 2 & 1,4 & 0 & 0,0 & 11 & 4,6 \\
\hline Trabajo & 2 & 2,2 & 53 & 36,1 & 0 & 0,0 & 55 & 22,9 \\
\hline Asunto personal & 10 & 11,0 & 30 & 20,4 & 1 & 50,0 & 41 & 17,1 \\
\hline Comercio & 1 & 1,1 & 43 & 29,3 & 0 & 0,0 & 44 & 18,3 \\
\hline in between & 0 & 0,0 & 10 & 6,8 & 0 & 0,0 & 10 & 4,2 \\
\hline Total & 91 & 100 & 147 & 100 & 2 & 100 & 240 & 100 \\
\hline
\end{tabular}

Fuente: Elaboración propia. Encuesta FONDECYT No 1150123

Al revisar por sexo (Cuadro $\left.N^{\circ} 4\right)$, destacamos que entre los nacidos en Perú la mayoría de los encuestados que cruzan la frontera son hombres $(59,2 \% \%)$ al contrario de los nacidos en Chile que fueron mayoritariamente mujeres $(63,7 \%)$. En cuanto a los grupos etarios, hay una diferencia significativa según el país, las personas de origen chileno encuestadas son mayores que las de origen peruano. Distinguimos que los hombres de Chile están situados mayoritariamente entre los grupos de 31 a 50 años. Los hombres de Perú entre menos de 30 hasta 40 años. En relación a las mujeres, vemos que las de origen chileno tienen entre 41 y 60 años y las nacidas en Perú menos de 30 hasta 40. Paradójicamente, al observar el nivel educativo de estas personas, podemos constatar que la gran mayoría de la muestra, indistintamente de su nacionalidad declara haber cursado estudios hasta el nivel secundario.

Cuadro $\mathrm{N}^{\circ} 4$

País de nacimiento por sexo de los encuestados

\begin{tabular}{|l|r|r|r|r|r|r|}
\hline \multirow{2}{*}{ Nacionalidad } & \multicolumn{2}{|c|}{ Hombre } & \multicolumn{2}{c|}{ Mujer } & \multicolumn{2}{c|}{ Total } \\
\cline { 2 - 8 } & \multicolumn{1}{|c}{$\mathrm{n}^{\circ}$} & \multicolumn{1}{c|}{$\%$} & $\mathrm{n}^{\circ}$ & \multicolumn{1}{c|}{$\%$} & $\mathrm{n}^{\circ}$ & \multicolumn{1}{c|}{$\%$} \\
\hline Chilena & 33 & 27,3 & 58 & 48,7 & 91 & 37,9 \\
\hline Peruana & 87 & 71,9 & 60 & 50,4 & 147 & 61,3 \\
\hline Boliviana & 0 & 0,0 & 1 & 0,8 & 1 & 0,4 \\
\hline Ecuatoriana & 1 & 0,8 & 0 & 0,0 & 1 & 0,4 \\
\hline Total & 121 & 100 & 119 & 100 & 240 & 100 \\
\hline
\end{tabular}

Fuente: Elaboración propia. Encuesta FONDECYT Nº 1150123.

Otro patrón muy diferenciado según la nacionalidad son las modalidades de viaje (Cuadro 5); el primero surge al preguntar si viajan solos o acompañados habitualmente, los chilenos y chilenas en general dicen viajar acompañados $(90,1 \%$ y los peruanos y peruanas solos $(86,2 \%)$. 
Cuadro $\mathrm{N}^{\circ} 5$

Modalidad de viaje por nacionalidad

\begin{tabular}{|l|r|r|r|r|r|r|r|r|}
\hline \multirow{2}{*}{ Modalidad de viaje } & \multicolumn{2}{|c|}{ Chilena } & \multicolumn{2}{c|}{ Peruana } & \multicolumn{2}{c|}{ Otra } & \multicolumn{2}{c|}{ Total } \\
\cline { 2 - 9 } & \multicolumn{1}{c|}{$\mathrm{n}^{\circ}$} & \multicolumn{1}{c|}{$\%$} & \multicolumn{1}{c|}{$\mathrm{n}^{\circ}$} & \multicolumn{1}{c|}{$\%$} & \multicolumn{1}{c|}{$\mathrm{n}^{\circ}$} & \multicolumn{1}{c|}{$\%$} & \multicolumn{1}{c|}{$\mathrm{n}^{\circ}$} & \multicolumn{1}{c|}{$\%$} \\
\hline Sólo & 9 & 9,9 & 125 & 86,2 & 0 & 0,0 & 134 & 56,3 \\
\hline Acompañado & 82 & 90,1 & 20 & 13,8 & 2 & 100,0 & 104 & 43,7 \\
\hline Total & 91 & 100 & 145 & 100 & 2 & 100 & 238 & 100 \\
\hline
\end{tabular}

Fuente: Elaboración propia. Encuesta FONDECYT Nº 1150123.

Asimismo, el medio de transporte indica diferencias entre los residentes en Arica y Tacna respectivamente (Cuadro $N^{\circ} 6$ ). Del total de los encuestados chilenos, la mayoría viaja a Tacna en auto propio, seguido por un grupo menor que va en "micro" (autobus). Contrariamente, para los encuestados peruanos que cruzan la frontera la principal opción es la "micro", seguido del taxi y luego el auto propio. Es importante señalar que el valor del cruce en micro es $\cup \$ 4$, la mitad del valor del cruce en taxi $\cup \$ 8$ aproximadamente.

Cuadro $N^{\circ} 6$

Medio de transporte por el que cruza la frontera por país de nacimiento

\begin{tabular}{|l|r|r|r|r|r|r|r|r|}
\hline \multirow{2}{*}{ Medio de transporte } & \multicolumn{2}{|c|}{ Chilena } & \multicolumn{2}{c|}{ Peruana } & \multicolumn{2}{|c|}{ Otra } & \multicolumn{2}{|c|}{ Total } \\
\cline { 2 - 9 } & \multicolumn{1}{|c}{$\mathrm{n}^{\circ}$} & \multicolumn{1}{c|}{$\%$} & \multicolumn{1}{c|}{$\mathrm{n}^{\circ}$} & \multicolumn{1}{c|}{$\%$} & $\mathrm{n}^{\circ}$ & \multicolumn{1}{c|}{$\%$} & $\mathrm{n}^{\circ}$ & \multicolumn{1}{c|}{$\%$} \\
\hline Taxi & 8 & 9,8 & 30 & 21,0 & 0 & 0 & 38 & 16,7 \\
\hline Micro & 11 & 13,4 & 91 & 63,6 & 0 & 0 & 102 & 44,9 \\
\hline En auto propio & 61 & 74,4 & 19 & 13,3 & 2 & 100 & 82 & 36,1 \\
\hline En auto arrendado & 0 & 0,0 & 1 & 0,7 & 0 & 0 & 1 & 0,4 \\
\hline En el auto de otra persona & 2 & 2,4 & 2 & 1,4 & 0 & 0 & 4 & 1,8 \\
\hline Total & 82 & 100 & 143 & 100 & 2 & 100 & 227 & 100 \\
\hline
\end{tabular}

Fuente: Elaboración propia. Encuesta FONDECYT Nº 1150123.

La encuesta consideró una categoría de migrante, es decir aquellas personas que declararon haber nacido en un país pero que residen en otro (Cuadro $N^{\circ} 7$ ). La gran mayoría de los encuestados de nacionalidad chilena vive en Arica, y sólo dos $(2,2 \%)$ personas pueden ser consideradas migrantes, es decir personas que nacieron en Chile, pero que residen en Tacna. En el caso de los de nacionalidad peruana encontramos más migrantes, 18 personas, que representan al $12,2 \%$ del total de los peruanos. Sin embargo de las 129 personas que declaran residir en Tacna 41 (31,8\%) trabaja en Arica (Cuadro $N^{\circ} 8$ ). Por tanto lo que advertimos es que la migración no es necesariamente el fenómeno más extendido sino la movilidad laboral transfronteriza, es decir, cruzar para trabajar entre 1 y 7 días y regresar a Tacna donde normalmente residen las personas que están en esta condición y que respondieron la encuesta. 


\section{Cuadro $\mathrm{N}^{\circ} 7$}

Lugar residencia de los encuestados por nacionalidad

\begin{tabular}{|l|r|r|r|r|r|r|r|r|}
\hline \multirow{2}{*}{$\begin{array}{l}\text { Lugar de } \\
\text { residencia }\end{array}$} & \multicolumn{2}{|c|}{ Chilena } & \multicolumn{2}{c|}{ Peruana } & \multicolumn{2}{c|}{ Otra } & \multicolumn{2}{c|}{ Total } \\
\cline { 2 - 10 } & \multicolumn{1}{|c|}{$\mathrm{n}^{\circ}$} & \multicolumn{1}{c|}{$\%$} & \multicolumn{1}{c|}{$\mathrm{n}^{\circ}$} & \multicolumn{1}{c|}{$\%$} & \multicolumn{1}{c|}{$\mathrm{n}^{\circ}$} & \multicolumn{1}{l}{$\%$} & $\mathrm{n}^{\circ}$ & \multicolumn{1}{c|}{$\%$} \\
\hline Arica & 89 & 97,8 & 18 & 12,2 & 1 & 50,0 & 108 & 45,0 \\
\hline Tacna & 2 & 2,2 & 129 & 87,8 & 1 & 50,0 & 132 & 55,0 \\
\hline Total & 91 & 100 & 147 & 100 & 2 & 100 & 240 & 100 \\
\hline
\end{tabular}

Fuente: Elaboración propia. Encuesta FONDECYT N 1150123.

Cuadro $N^{\circ} 8$

Motivos para cruzar según lugar de residencia y nacionalidad

\begin{tabular}{|c|c|c|c|c|c|}
\hline \multirow{2}{*}{\begin{tabular}{|l|} 
Lugar de \\
Residencia
\end{tabular}} & \multirow{2}{*}{ Motivo de viaje } & Chilena & Peruana & Otra & Total \\
\hline & & $\mathrm{n}^{\circ}$ & $\mathrm{n}^{\circ}$ & $n^{\circ}$ & $n^{\circ}$ \\
\hline \multirow{8}{*}{ Arica } & Turismo médico & 35 & 0 & 0 & 35 \\
\hline & Turismo general & 32 & 1 & 1 & 34 \\
\hline & Turismo de compra & 9 & 0 & 0 & 9 \\
\hline & Trabajo & 2 & 12 & 0 & 14 \\
\hline & Asunto personal & 10 & 3 & 0 & 13 \\
\hline & Comercio & 1 & 1 & 0 & 2 \\
\hline & in between & 0 & 1 & 0 & 1 \\
\hline & Total & 89 & 18 & 1 & 108 \\
\hline \multirow{8}{*}{ Tacna } & Turismo médico & 1 & 0 & 0 & 1 \\
\hline & Turismo general & 1 & 8 & 0 & 9 \\
\hline & Turismo de compra & 0 & 2 & 0 & 2 \\
\hline & Trabajo & 0 & 41 & 0 & 41 \\
\hline & Asunto personal & 0 & 27 & 1 & 28 \\
\hline & Comercio & 0 & 42 & 0 & 42 \\
\hline & in between & 0 & 9 & 0 & 9 \\
\hline & Total & 2 & 129 & 1 & 132 \\
\hline \multirow{8}{*}{ Total } & Turismo médico & 36 & 0 & 0 & 36 \\
\hline & Turismo general & 33 & 9 & 1 & 43 \\
\hline & Turismo de compra & 9 & 2 & 0 & 11 \\
\hline & \begin{tabular}{|l|} 
Trabajo \\
\end{tabular} & 2 & 53 & 0 & 55 \\
\hline & Asunto personal & 10 & 30 & 1 & 41 \\
\hline & Comercio & 1 & 43 & 0 & 44 \\
\hline & in between & 0 & 10 & 0 & 10 \\
\hline & Total & 91 & 147 & 2 & 240 \\
\hline
\end{tabular}

Fuente: Elaboración propia. Encuesta FONDECYT Nº 1150123. 
El Cuadro $N^{\circ} 8$ expresa lo que ocurre de manera similar en otras regiones fronterizas como la de México-Estados Unidos y su par Mexicali/Caléxico con las personas que cruzan por motivos laborales pero que no cambian de residencia (commuters). Es el caso de los hombres que cruzan a diario en vehículo, fundamentalmente profesionales, entre ellos maestros, médicos o técnicos de maquila. Como señala Parella "cuando se trata de maestros o médicos con título no homologado en los Estados Unidos, vivir en la frontera es una forma de poder residir en Estados Unidos y desarrollar un empleo cualificado en México" (Parella, 2014: 61). En otros puntos de América y Europa ocurren fenómenos similares como es el caso de los guatemaltecos que van a trabajar a México (Chiapas) (Ángeles et al., 2008) o mujeres marroquíes que comercian y trabajan en el servicio doméstico en Ceuta o Melilla (Soriano y Fuentes) o las poblaciones de Tabatinga y Leticia que aprovechan las diferencias cambiarias para comprar más de acuerdo a las oscilaciones de la moneda (Aponte, 2012), por mencionar algunos casos. Estos movimientos de población son los que han invitado a discutir los alcances de la noción de migración y a utilizar la de movilidad que no implica cambio de residencia habitual, ya que permanecen durante un tiempo corto en el lugar de destino (Castillo y Nájera, 2014: 19). De hecho, el tiempo de estadía declarado al momento de la aplicación de la encuesta (¿Por cuánto tiempo cruza esta vez?) demuestra que los cruzadores están en permanente circularidad, la gran mayoría va por el día o por un tiempo máximo de siete días.

\section{Movilidades y prácticas socio-espaciales fronterizas entre Arica y Tacna}

Como hemos señalado anteriormente, las prácticas socio-espaciales fronterizas dan cuenta de distintos tipos de movilidad. Con el fin de identificarlos, describirlos y analizarlos se construyó una nueva variable a partir de la base de datos inicial de la encuesta, que denominamos "tipos de movilidad", correspondiente al cruce de diversas preguntas según los casos, pero manteniendo como base el motivo del cruce declarado inicialmente. De esta manera, se puede afirmar que los tipos de movilidad son mutuamente excluyentes, porque se mide el movimiento del momento de aplicación de la encuesta. De acuerdo a la encuesta consideramos la movilidad como aquellas prácticas socio-espaciales que no implican cambio de residencia, pero que suponen una circulación fronteriza frecuente. Aquellos que se declararon migrantes, es decir, que cambiaron de residencia y país, mantienen prácticas de movilidad más allá de su establecimiento en Arica o Tacna. De esta manera se definió para cada encuestado/a un tipo de movilidad, que procederemos a describir a continuación.

Como señalamos más arriba distinguimos dos tipos de prácticas socio-espaciales: productivas y reproductivas. Las primeras se expresan en mayor medida en la dirección del flujo Tacna-Arica y representan el $60 \%$ de las prácticas. Y las segundas en el sentido contrario, Arica-Tacna representan $79 \%$ de las prácticas. Estas a su vez se subdividen en las que aquí detallamos:

Entre las prácticas productivas que dan lugar la movilidad laboral transfronteriza distinguimos quienes realizan actividades laborales dependientes e independientes y comerciales al otro lado de la frontera sin residir en la ciudad vecina. Para mayor claridad desagregamos las prácticas en cinco tipos de acuerdo a lo que respondieron las y los encuestados. Entre ellos: 
- Movilidad laboral remunerada: se trata de trabajadores que tienen contrato laboral formal o informal (de palabra) por días, semanas y mensuales que representan el $30 \%$ de las prácticas productivas en el sentido de la movilidad entre Tacna y Arica y el $33 \%$ en el sentido Arica-Tacna (Cuadro Nº 9).

- Movilidad laboral independiente: son las personas que trabajan por cuenta propia o buscan trabajo sin un contrato. Esta movilidad representa el $12 \%$ de las prácticas productivas de personas de nacionalidad peruana desde Tacna hacia Arica y un $2 \%$ de los de nacionalidad chilena, y no se expresa en el sentido inverso (Cuadro $N^{\circ} 9$ ).

- Movilidad laboral comercial: son comerciantes que cruzan la frontera para comprar productos en un lado para venderlos luego en el otro. Del 100\% de quienes cruzan de Arica hacia Tacna, el 56\% lo hace por motivo de "movilidad laboral comercial"; mientras que del $100 \%$ de quienes cruzan de Tacna hacia Arica, el 37\% lo hace por ese motivo; independiente de su nacionalidad (Cuadro $N^{\circ}$ 9). Cruzan la frontera para comprar productos (Alimenticios, detergentes, ropa usada y nueva, en Arica o Tacna) de un lado y luego venderlos en el otro. Esta movilidad ha sido descrita como un grupo clave en la circulación de mercancías en el Terminal Internacional de Arica, en particular la participación de las mujeres peruanas comerciantes independientes de la ropa americana (Lube et al., 2013; Valdebenito y Lube, 2014: 9-10). También la movilidad laboral comercial se sitúa en quienes se dedican al intercambio de productos usados, tal como lo analiza Graña (2001) al referirse a las "cambio caseras". Se trata de un comercio puerta a puerta, realizado por mujeres que recorren la ciudad de Arica a pie ofreciendo productos peruanos o haciendo trueques, principalmente de productos de plástico por ropa o zapatos usados, pero en buen estado (Graña, 2001: 1209). Podemos asociar estas actividades comerciales a lo expresado por Tarrius como componente de una "economía subterránea" que reorganiza las sociedades y desde lo local plantea otro enfoque de la globalización (Tarrius, 2007). El cruce de la frontera implica un control de Aduanas al que generalmente escapan lo/as comerciantes por tratarse, en principio, de una importación de productos que no superan los límites establecidos para el pago de impuestos aduaneros, que es de 1.000 USD $^{15}$. La arista científica que se abre en este sentido es inmensurable, ya que el mismo autor plantea que "estos fenómenos contribuyen a la vasta renegociación contemporánea de las ideologías y de los comportamientos colectivos" (Tarrius, 2001), lo que nos desafía a indagar en el futuro sobre los significados y repercusiones de esta economía a distintos niveles.

- Movilidad laboral in between. Corresponden a personas que trabajan en torno a la frontera que facilitan el desplazamiento de los cruzadores en el espacio circulatorio entre las dos ciudades, entre ellos se encuentran: taxistas, choferes y auxiliares de buses. Esta movilidad representa un $10 \%$ de las prácticas productivas en el flujo Arica-Tacna y $6 \%$ en la dirección contraria, desde Tacna hacia Arica (Cuadro Nº 9). 
- Movilidad laboral de temporada: corresponde a trabajadores estacionales que laboran principalmente en los valles de Azapa y Lluta en Arica en tareas agrícolas, "que únicamente se desplazan por un periodo específico a trabajar en la cosecha de algún producto agrícola" (Castillo y Nájera, 2014: 19).

Este último perfil no pudo ser analizado a partir de la encuesta, dado que la mayoría de éstos fueron temerosos a responder y a informar sobre las actividades que realizan en Arica, posiblemente por trabajar sin autorización. Suponemos que gran parte de ellos están comprendidos en el perfil relacionado a "asunto personal", ya que varios peruanos encuestados en la madrugada del lunes o a última hora del domingo en la noche declararon "visitar a parientes o amigos". Sin embargo la información recogida previamente nos indica que esta población participa de las labores agrícolas en los valles de la región, Azapa y Lluta ${ }^{16}$. Según información recogida en el trabajo de campo los trabajadores agrícolas de temporada son hombres y mujeres de origen boliviano y peruano, que van y vienen usando los convenios adoptados entre los países; en el primer caso entran como turistas por periodos de hasta 90 días, siendo contratados por antiguas familias bolivianas radicadas en los valles y propietarias (Tapia, 2015). En el caso de los peruanos se trata de períodos más cortos (hasta 5 días), regresando a sus hogares los fines de semana, siendo contratados como jornaleros desde el Terminal Internacional de Arica (Lube-Guizardi et al., 2015; Valdebenito y Lube, 2014). Otra característica es que en ambos casos, se trataría de poblaciones quechua y aymara boliviano y chileno. El principal interés en ambos grupos radica en el diferencial económico que implica el cambio de la moneda, al obtener remuneraciones de entre dos y hasta diez veces más de lo que se paga en sus países de origen por labores similares. Esta mano de obra cubre la demanda de fuerza de trabajo nacional que se ha orientado hacia otros sectores de la economía, principalmente la minería. Sin embargo, la principal característica de las labores agrícolas es la precariedad y vulnerabilidad del trabajo, ya que la gran mayoría trabaja sin autorización y son fácilmente víctimas del abuso o de la inseguridad laboral.

Entre las prácticas reproductivas distinguimos la movilidad turística, la movilidad por salud y la movilidad por asuntos personales. Para las dos primeras movilidades vemos claramente que la dirección del flujo es principalmente desde Arica hacia Tacna, en cambio la movilidad por asuntos personales está concentrada en el flujo de Tacna hacia Arica.

- Movilidad turística: se refiere a las personas que cruzan la frontera por los siguientes motivos: - fines gastronómicos

- fines recreativos y de ocio

- comprar productos más baratos o variados que no encuentran en el lugar de residencia.

Esta movilidad representa el $48 \%$ de las prácticas reproductivas desde Arica hacia Tacna (Cuadro $\mathrm{N}^{\circ}$ 9).

- Movilidad por salud: corresponde a las personas que cruzan con fines médicos, tanto para atenderse en servicios de salud peruanos como para comprar medicamentos, lentes $u$ otros. Esta movilidad se expresa principalmente en el flujo Arica-Tacna, representando un $36 \%$ de las prácticas reproductivas en esta dirección (Cuadro №9).

16 Entrevistas realizadas en el FONDECYT de Iniciación Nº 1110096 
- Movilidad por asuntos personales: se refiere a las personas que cruzan para visitar familiares o amigos, resolver problemas o trámites personales. Inversamente a la tendencia de las otras prácticas reproductivas, esta movilidad se expresa principalmente en la dirección Tacna-Arica, representando un 39\% de las prácticas reproductivas (Cuadro № 9). Como ya lo señalamos, esta opción puede esconder el principal motivo de las personas de nacionalidad peruana ya que probablemente muchos de ellos lo hacen para buscar trabajo o trabajar tal vez sin autorización.

En el Cuadro $\mathrm{N}^{\circ} 9$ podemos observar el detalle de los tipos de movilidad en función de las prácticas socioespaciales que se despliegan en las dos direcciones: desde Tacna hacia Arica y desde Arica hacia Tacna.

\section{Cuadro $\mathrm{N}^{\circ} 9$}

Tipos de movilidad por prácticas socio-espaciales

\begin{tabular}{|c|c|c|c|c|c|c|c|c|c|}
\hline \multicolumn{2}{|c|}{$\begin{array}{l}\text { Tipo de movilidad por prácticas } \\
\text { socio-espaciales }\end{array}$} & \multicolumn{4}{|c|}{ Tacna-Arica } & \multicolumn{4}{|c|}{ Arica-Tacna } \\
\hline Nacionalidad & Prácticas productivas & Hombres & Mujeres & & & Hombres & Mujeres & & \\
\hline \multirow{5}{*}{ Chilena } & $\begin{array}{l}\text { 1. Movilidad laboral } \\
\text { remunerada }\end{array}$ & 0 & 0 & 0 & $0 \%$ & 0 & 0 & 0 & $0 \%$ \\
\hline & $\begin{array}{l}\text { 2. Movilidad laboral } \\
\text { independiente }\end{array}$ & 2 & 0 & 2 & $2 \%$ & 0 & 0 & 0 & $0 \%$ \\
\hline & $\begin{array}{l}\text { 3. Movilidad laboral } \\
\text { comercial }\end{array}$ & 0 & 0 & 0 & $0 \%$ & 1 & 0 & 1 & $6 \%$ \\
\hline & $\begin{array}{l}\text { 4. Movilidad laboral in } \\
\text { between }\end{array}$ & 0 & 0 & 0 & $0 \%$ & 0 & 0 & 0 & $0 \%$ \\
\hline & $\begin{array}{l}\text { 5. Trabajador que } \\
\text { busca empleo }\end{array}$ & 0 & 0 & 0 & $0 \%$ & 0 & 0 & 0 & $0 \%$ \\
\hline \multirow{5}{*}{ Peruana } & $\begin{array}{l}\text { 1. Movilidad laboral } \\
\text { remunerada }\end{array}$ & 15 & 13 & 28 & $30 \%$ & 2 & 4 & 6 & $33 \%$ \\
\hline & $\begin{array}{l}\text { 2. Movilidad laboral } \\
\text { independiente }\end{array}$ & 9 & 2 & 11 & $12 \%$ & 0 & 0 & 0 & $0 \%$ \\
\hline & $\begin{array}{l}\text { 3. Movilidad laboral } \\
\text { comercial }\end{array}$ & 15 & 19 & 34 & $37 \%$ & 6 & 4 & 10 & $56 \%$ \\
\hline & $\begin{array}{l}\text { 4. Movilidad laboral in } \\
\text { between }\end{array}$ & 7 & 2 & 9 & $10 \%$ & 1 & 0 & 1 & $6 \%$ \\
\hline & $\begin{array}{l}\text { 5. Trabajador que } \\
\text { busca empleo }\end{array}$ & 5 & 3 & 8 & $9 \%$ & 0 & 0 & 0 & $0 \%$ \\
\hline \multirow[t]{2}{*}{ TOTALES } & & 53 & 39 & 92 & $100 \%$ & 10 & 8 & 18 & $100 \%$ \\
\hline & $\begin{array}{l}\text { Prácticas } \\
\text { reproductivas }\end{array}$ & & & & & & & & \\
\hline \multirow{3}{*}{ Chilena } & 1. Movilidad turística & 6 & 3 & 9 & $15 \%$ & 9 & 24 & 33 & $48 \%$ \\
\hline & 2. Movilidad por salud & 2 & 9 & 11 & $18 \%$ & 7 & 18 & 25 & $36 \%$ \\
\hline & $\begin{array}{l}\text { 3. Movilidad por } \\
\text { asuntos personales }\end{array}$ & 3 & 2 & 5 & $8 \%$ & 3 & 2 & 5 & $7 \%$ \\
\hline
\end{tabular}


Continuación Cuadro $N^{\circ} 9$

\begin{tabular}{|l|l|r|r|r|r|r|r|r|r|}
\hline \multicolumn{2}{|l|}{$\begin{array}{l}\text { Tipo de movilidad por prácticas } \\
\text { socio-espaciales }\end{array}$} & \multicolumn{4}{|c|}{ Tacna-Arica } & \multicolumn{4}{|c|}{ Arica-Tacna } \\
\hline Nacionalidad & Prácticas productivas & Hombres & Mujeres & & Hombres & Mujeres & \\
\hline \multirow{3}{*}{ Peruana } & 1. Movilidad turística & 8 & 3 & 11 & $18 \%$ & 0 & 0 & 0 & $0 \%$ \\
\cline { 2 - 11 } & 2. Movilidad por salud & 0 & 0 & 0 & $0 \%$ & 0 & 0 & 0 & $0 \%$ \\
\cline { 2 - 11 } & $\begin{array}{l}\text { 3. Movilidad por } \\
\text { asuntos personales }\end{array}$ & 18 & 6 & 24 & $39 \%$ & 3 & 2 & 5 & $7 \%$ \\
\hline Boliviana & 1. Movilidad turística & 0 & 1 & 1 & $2 \%$ & 0 & 0 & 0 & $0 \%$ \\
\hline Ecuatoriano & $\begin{array}{l}\text { 3. Movilidad por } \\
\text { asuntos personales }\end{array}$ & 0 & 0 & 0 & $0 \%$ & 1 & 0 & 1 & $1 \%$ \\
\hline TOTALES & & 37 & 24 & 61 & $100 \%$ & 23 & 46 & 69 & $100 \%$ \\
\hline
\end{tabular}

Fuente: Elaboración propia. Encuesta FONDECYT Nº 1150123.

Al analizar esta tabla, se constata que las prácticas productivas están marcadas por flujos desde Tacna hacia Arica, principalmente de peruanos. Por el contrario las prácticas reproductivas están más diversificadas, siendo porcentualmente mayor la movilidad por salud. Se caracterizan por ser personas que ingresan a Chile, es decir, van de Tacna a Arica, que vienen de regreso (porque son chilenas y chilenos), y que cruzaron por motivos de salud. Los datos asociados a la movilidad por asuntos personales son particularmente interesantes, ya que responden a los supuestos anteriormente mencionados, es decir, trabajadores residentes en Tacna que cruzan a Arica para trabajar en los valles o en trabajos de reformas u obras menores.

Por último el estudio de los datos de la PDI y los resultados de la encuesta muestran que esta frontera no sólo presenta un intenso flujo de personas hacia ambos lados sino que los motivos y por tanto las movilidades a que dan lugar son diferentes, tanto si se trata de residentes de Arica (chilenos) o residentes de Tacna (peruanos). Por un lado, distinguimos distintos tipos de movilidades que aparecen: migrantes, trabajadores transfronterizos, comerciantes, turistas, que se dividen en turismo médico, turismo de ocio y turismo de compra, y pasadores de frontera o in between. La intensidad de los flujos demuestra la existencia de un mercado laboral fronterizo para la fuerza de trabajo peruana que aprovecha las oportunidades laborales y comerciales que ofrece Arica. Por otra parte, la oferta turística y especialmente sanitaria de Tacna es valorada por los chilenos al encontrar en este cruce mayor accesibilidad y rapidez en la atención médica. Asimismo aspectos altamente valorables como la gastronomía, entretenimiento y otros productos y servicios a bajo precio favorecen el cruce. Constatamos que ambos grupos aprovechan las diferencias económicas en la frontera, es decir las diferencias de salario y de precios que existen a uno y otro lado de la frontera y las ventajas que implica comprar, trabajar o comer por el hecho de cruzar a Arica o a Tacna. Cuando preguntamos por las ventajas de cruzar la frontera se aprecian similitudes en ambos casos tanto para quienes vienen desde Tacna o cruzan desde Arica la cercanía geográfica es lo más valorado. Sin embargo para quienes se dirigen desde Tacna hacia Arica por trabajo o comercio los mejores sueldos y el valor de los productos más baratos para comerciar son los factores más determinantes. Para quienes cruzan en sentido inverso, es decir de Arica a Tacna, lo barato de los productos, una mayor oferta de los mismos y mayores opciones de entretención y gastronómicas son las más importantes. Las distintas valoraciones están en 
correspondencia con el tipo de prácticas socio-espaciales, por lo que podemos presumir que mantenerse estos rasgos las continuarán movilidades entre estas dos ciudades y se consolidará el territorio circulatorio.

\section{Conclusiones}

Los estudios sobre movilidad en contextos fronterizos nos desafían a interrogar las categorías utilizadas hasta la fecha en los estudios migratorios (migrations studies) y los estudios fronterizos (border studies). Por una parte las investigaciones sobre migración más recientes advierten sobre la visibilización de distintos tipos de desplazamientos más allá de los motivos laborales, es decir, de la migración económica; y por otro sobre la multiplicación de una variedad de movilidades que no implican necesariamente un cambio de residencia. Si bien los motivos económicos siguen manteniendo una centralidad en la migración fronteriza e internacional, los desplazamientos en regiones fronterizas invitan a atender a otros motivos fuera de la atracción que ejercen los mercados de trabajo o la explotación de zonas de rentas. Asimismo, los contextos fronterizos ponen a prueba las categorías binarias que han predominado en los estudios migratorios como origen y destino o temporal y definitivo, por mencionar algunos. Por tanto, las movilidades por diversos motivos (laborales, médico, turístico, asuntos personales o de ocio) involucran en este caso a un espacio binacional (Tacna/Perú y Arica/Chile) articulan lugares de salida con los de tránsito y de entrada lo que nos llevan a plantear la existencia de un territorio circulatorio y no movimientos migratorios como se ha venido estudiando.

Por otro lado, la inclusión de la frontera y la reciente producción de los border studies nos permiten comprender los procesos de intercambio e interacción más allá del límite o de lo que separa a dos o más estados-naciones. Desde hace mucho tiempo los espacios o regiones fronterizos han pasado de ser un espacio de separación a lugares de interacción por abajo, más allá del influjo geopolítico que contienen en su definición. No se trata de creer que las fronteras han perdido su poder o capacidad de contener o filtrar, sino de comprender que para sus habitantes el cruce de la frontera se convierte en un recurso más allá de los eventuales impedimentos o trabas. Por tanto, la oscilación entre cierre y apertura, interacción y restricción conviven y no desaparecen sólo por el reforzamiento del límite o por la apertura de las fronteras. En este sentido las coyunturas históricas, los reavivamientos del nacionalismo y los litigios latentes sobre delimitación ayudan a comprender esta oscilación, así como otros fenómenos que desbordan este estudio, pero que somos conscientes que existen como la discriminación hacia el extranjero y la xenofobia.

Los aportes de la geografía social francesa y el influjo del nacionalismo metodológico en los estudios migratorios y de frontera han permitido develar los fenómenos menos atendidos por ambos cuerpos de estudios, pero que sin duda han ido creciendo en las Ciencias Sociales. El renacimiento de los estudios de frontera en distintas latitudes y en América Latina ha enriquecido nuestro conocimiento de dichos espacios y ampliado la mirada sobre los fenómenos que allí ocurren. La inclusión en el estudio de los espacios fronterizos de la movilidad humana, las desigualdades a uno u otro lado la frontera, la complementariedad económica y de oportunidades, permiten comprender cómo se configura un territorio circulatorio. En el caso de estudio y de manera similar a lo que pasa en otras partes del mundo, las diferencias económicas, sociales y laborales entre Tacna y Arica producen complementariedad de los espacios fronterizos que se multiplica por la adyacencia geográfica y la existencia de un marco jurídico específico sobre in- 
greso y tránsito que favorece el flujo entre ambas ciudades. Es posible que los significados dados a las prácticas fronterizas en cada caso puedan ser distintos y al mismo tiempo estar vinculados o no con la ganancia económica, que es un tema a seguir explorando en esta investigación, pero que claramente están presentes y ayudan a comprender la intensidad del cruce.

A diferencia de lo que se puede pensar a priori, el vigor de los flujos es en ambas direcciones (Arica-Tacna/Tacna-Arica) y da cuenta de una situación de interdependencia y complementariedad que permite imaginar la posibilidad de agilizar y facilitar el tránsito transfronterizo. Esto con el fin de impulsar la integración del territorio circulatorio a nivel binacional y, al mismo tiempo, acercar las poblaciones vecinas, como estrategia de desarrollo y de mantención de la paz.

\section{Referencias bibliográficas}

ALEGRÍA, T. Juntos pero no revueltos: ciudades en la frontera México-Estados Unidos. Revista Mexicana de Sociología, 2000, Nº62, p. 89-107

APONTE, J. Comercio y ocio en la transformación del espacio urbano fronterizo de Leiticia y Tabatinga. En: ZÁRATE, C. (editor). Espacios urbanos y sociedades transfronterizas en la Amazonía. Leticia: Universidad Nacional de Colombia, 2012, p. 205-235.

BENEDETTI, A. y SALIZZI, E. Llegar, pasar, regresar a la frontera. Aproximación al sistema de movilidad argentino-boliviano. Transporte y Territorio, 2011, № 4, p. 148-179.

CASTILLO, M. y NÁJERA, J. México como país de origen, tránsito y destino de migrantes, una revisión a partir de la emif norte y la emif sur. En: CONSEJO NACIONAL DE POBLACIÓN (editor). 20 años de la Encuesta sobre Migración en la Frontera Norte de México. México D.F.: Consejo Nacional de Población, 2014, p. 17-35.

CAVALCANTI, L. y PARELLA, S. El retorno desde una perspectiva transnacional. REMHU. Revista Interdisciplinar da Mobilidade Humana, 2013, Vol. 21, № 41, p. 9-20.

CORTÉS, G. Migraciones, construcciones transnacionales y prácticas de circulación. Un enfoque desde el territorio. Párrafos Geográficos, 2009, Vol. 8, № 1, p. 35-53

CRUZ, R. y QUINTERO, C. Ires y venires. Movimientos migratorios en la frontera norte de México. México D.F.: El Colegio de la Frontera Norte/El Colegio de San Luís, 2011.

CHAVEZ, S. Border Lives: Fronterizos, Transnational Migrants, and Commuters in Tijuana. New York: Oxford University Press, 2016.

DILLA, H. Las ciudades en las fronteras: introducción a un debate. En: DILLA, H. (editor). Ciudades en las fronteras. Aproximaciones críticas a los complejos urbanos transfronterizos. Santo Domingo: Editora Manatí, 2008, p. 17-29.

DURAND, J. Los inmigrantes también emigran: la migración de retorno como corolario del proceso. REMHU. Revista Interdisciplinar da Mobilidade Humana, 2006, № 26-27, p. 167-189. 
FIMBRES, N. Emigración, inmigración y retorno: el ciclo de los inmigrantes Mexicanos en Caléxico, California, EUA. Estudios Fronterizos, 2000, Vol. 1, № 2, p. 93-120.

GIELIS, R. Borders make the difference: Migrant transnacionalism as a border experience. Tijdschrift voor Economische en Sociale Geografie, 2009, Vol. 100, № 5, p. 598-609.

GONZÁLEZ, S. El Dios Cautivo. Las ligas patrióticas en la chilenización compulsiva de Tarapacá (1910-1922). Santiago de Chile: LOM, 2004.

GONZÁLEZ, S. La llave y el candado: el conflicto entre Perú y Chile por Tacna y Arica (1883-1929. Santiago de Chile: LOM, 2008.

GRAÑA, F. Cambio casera: comercio y relaciones fronterizas en el extremo norte de Chile. En: Actas del $4^{\circ}$ Congreso Chileno de Antropología, Simposio Fronteras y Corredores, 2001. Disponible en Internet:

http://www.slideshare.net/granapezoa/actas-4-congreso-antropologia

GRIMSON, A. y LUBE-GUIZARDI, M. Matices y límites del transnacionalismo: los contextos de la migración en Chile. En: LUBE-GUIZARDI, M. y GRIMSON, A. (editores). Las fronteras transnacionales del transnacionalismo: límites y desbordes de la experiencia migrante en el centro y norte de Chile. Santiago de Chile: Ocho Libros, 2015, p.. 13-34.

HEYMAN, J. Construcción y uso de tipologías: movilidad geográfica en la frontera México-Estados Unidos. En: ARIZA, M. y VELASCO, L. (editor). Métodos cualitativos y su aplicación empírica. Por los caminos de la investigación sobre migración internacional. México D.F: Instituto de Investigaciones Sociales-UNAM/El Colegio de la Frontera Norte, 2012, p. 419-454.

HINOJOSA, A. Idas y venidas. Campesinos tarijeños en el norte argentino. La Paz: Fundación PIEB, 2000.

INSTITUTO NACIONAL DE ESTADISTICAS (INE). Proyecciones y estimaciones de población. Santiago de Chile: INE, s/f. Disponible en Internet:

http://palma.ine.cl/demografia/menu/EstadisticasDemograficas/proyecciones.aspx

JAQUET, H. Más allá de la frontera, las fronteras: una aproximación socioespacial a las situaciones fronterizas de Misiones, Argentina. En: DILLA ALFONSO, H. (editor). Ciudades en la frontera. Aproximaciones críticasa los complejos urbanos transfronterizos. Santo Domingo: Editora Manatí, 2008, p. 33-66.

LIBERONA, N. La rigidez de las fronteras. Inmigración e integración en Tarapacá (1990-2007). En: LUBE, M. y A. GRIMSON (editores). Las fronteras transnacionales del transnacionalismo: límites y desbordes de la experiencia migrante en el centro y norte de Chile. Santiago de Chile: Ocho Libros, 2015, p. 281-329.

LUBE-GUIZARDI, M.; HEREDIA, O.; MUÑOZ, A.; RIQUELME, G. y VALDEBENITO, F. Experiencia migrante y apropiaciones espaciales: una etnografía visual en las inmediaciones del Terminal Internacional de Arica (Chile). Revista de Estudios Sociales, 2013, Nº 48, p. 166-175. 
LUBE-GUIZARDI, M. y GRIMSON, A. (editores). Las fronteras del transnacionalismo. Límites y desbordes de la experiencia migrante en el centro y norte de Chile. Santiago de Chile: ocholibros, 2015.

LUBE-GUIZARDI, M.; VALDEBENITO, F.; LÓPEZ, E. y NAZAL, E. Condensaciones en el espacio hiperfronterizo: apropiaciones migrantes en la frontera norte de Chile. En: LUBE-GUIZARDI, M. y GRIMSON, A. (editores). Las fronteras del transnacionalismo. Límites y desbordes de la experiencia migrante en el centro y norte de Chile. Santiago de Chile: ocholibros, 2015, p. 224-257.

LUQUE, J.C. Asociaciones políticas de inmigrantes peruanos y la "Lima Chica" en Santiago de Chile. Migraciones Internacionales, 2007, Vol. 4, № 2, p. 121-150.

MALLIMACl, A.I. Movilidades y permanencias. Repensando la figura del movimiento en las migraciones. Revista de Temas de Antropología y Migración, 2012, p. 77-92.

MARCU, S. La movilidad transfronteriza de rumanos en España en tiempos de crisis. Revista Internacional de Sociología, 2013, Vol. 71, N 1, p. 115-141.

MATUS, J. (). Inmigrantes en Chile: más de dos tercios trabajan y el $42 \%$ cotiza en Fonasa. La Tercera, 21 de septiembre de 2014. Disponible en Internet:

http://www.latercera.com/noticia/nacional/2014/09/680-596709-9-inmigrantes-en-chile-mas-dedos-tercios-trabajan-y-el-42-cotiza-en-fonasa.shtml

MORALES, A. Desentrañando fronteras y sus movimientos transnacionales entre pequeños estados. Una aproximación desde la frontera Nicaragua-Costa Rica. En: ANGUIANO, M.E. y LÓPEZ, A.M. (editores). Migraciones y frontera. Nuevos contornos para la movilidad internacional. BarceIona: Icaria, 2010, p. 185-224.

ORGANIZACIÓN INTERNACIONAL PARA LAS MIGRACIONES (OIM). Perú, estadísticas de la emigración internacional de peruanos e inmigración de extranjeros 1990-2012. Lima: OIM, 2013.

PARELLA, S. Una aproximación al estudio empírico del retorno desde una perspectiva transnacional: El caso boliviano en España. En: PEDONE, C. y GIL, S. (editores). Políticas públicas, migración familiar y retorno de la población migrante latinoamericana en Cataluña: una perspectiva transnacional. Barcelona: Consorci Institut d'Infància i Món Urbà, 2013, p. 20-26.

PARELLA, S. Una exploración de las prácticas transfronterizas en la zona urbana Caléxico (Estados Unidos)-Mexicali (México). En: TAPIA, M. y GONZÁLEZ, A. (editores). Regiones fronterizas, migración y los desafíos para los estados nacionales latinoamericanos. Santiago de Chile: RIL Editores, 2014, p. 41-69.

ÁNGELES, H.; CASANUEVA, C. y ROJAS, M. Trabajo y migración femenina en la frontera sur de México. En: HERRERA, G. y RAMÍREZ, J. (editores). América Latina migrante: Estado, familias, identidades. Quito: FLACSO - Sede Ecuador, Ministerio de Cultura del Ecuador, 2008, p. 141-158.

SASSONE, S. Cruzar y vivir la frontera entre Bolivia y la Argentina. Entre el estado y el capital espacial del migrante. En: ANGUIANO, M.E. y LÓPEZ, A.M. (editores). Migraciones y frontera. Nuevos contornos para la movilidad internacional. Barcelona: CIDOB/Icaria, 2010, p. 225-257. 
SINATTI, G. Migraciones, transnacionalismo y locus de investigación: multi-localidad y la transición de 'sitios' a 'campos'. En: SOLĖ, C.; PARELLA, S. y CAVALCANTI, L. (editores). Nuevos retos del transnacionalismo en el estudio de las migraciones. Madrid: Ministerio de Trabajo e Inmigración, 2008, p. 93-112.

SOLIMANO, A.; SOLIMANO, A.; MELLADO, V.; ARAYA, C.; LAHOZ, S. y OCÓN, Y. Incorporación laboral de los migrantes en la Región Metropolitana de Chile. Santiago de Chile: OIM, 2012.

SORIANO, R. y FUENTES, M. La vulnerabilidad de las mujeres porteadoras de Ceuta y Melilla como sujeto de derechos humanos. En: KARLA, A. y IZCARA, S. (editores). Migrantes, transmigrantes, deportados y derechos humanos: un enfoque binacional. México D.F: Editorial de Fontamara, 2015, p. 117-140.

STEFONI, C. Inmigrantes en Chile. Una integración diferenciada al mercado laboral Migración y políticas sociales en América Latina. Brasil: SOPLA/Konrad Adenauer, 2009.

STEFONI, C. y FERNÁNDEZ, R. Mujeres inmigrantes en el trabajo doméstico: entre el servilismo y los derechos. En: STEFONI, C. (editor). Mujeres inmigrantes en Chile ¿Mano de obra o trabajadoras con derechos? Santiago de Chile: Universidad Alberto Hurtado, 2011, p. 45-72.

STEFONI, C. (editor). Mujeres inmigrantes en Chile ¿Mano de obra o trabajadoras con derechos? Santiago de Chile: Ediciones Universidad Alberto Hurtado, 2011.

TAPIA, M. Extranjeros fronterizos en las regiones extremas de Chile: entre migración y circulación. 1990-2014. En: ROJAS, N. y VICUÑA, J.T. (editores). Migración y Trabajo. Estudio y propuestas para la inclusión sociolaboral de migrantes en Arica. Santiago de Chile: Ciudadano Global /OIM, 2014, p. 31-55.

TAPIA, M. Frontera, movilidad y circulación reciente de peruanos y bolivianos en el norte de Chile Estudios atacameños. Arqueología y Antropología Surandinas, 2015, № 50, p. 195-213.

TAPIA, M. y PARELLA, S. Las regiones fronterizas para el estudio de la migración y la circulación. Un análisis de dos casos ilustrativos. En: LUBE-GUIZARDI, M. y GRIMSON, A. (editores). Las fronteras del transnacionalismo. Límites y desbordes de la experiencia migrante en el centro y norte de Chile. Santiago de Chile: ocholibros, 2015.

p. 173-206.

TAPIA, M. y RAMOS, R. Mujeres migrantes fronterizas en Tarapacá a principios del siglo XXI. EI cruce de las fronteras y las redes de apoyo. Polis. Revista Latinoamericana, 2013, Vol. 12, № 35, p. 229-257.

TARRIUS, A. Au-delà des États-nations: des sociétés de migrants. Revue européenne de migrations internationales, 2001, Vol. 17, N² 2, p. 37-61.

TARRIUS, A. La mundialización por abajo. El capitalismo nómada en el arco mediterráneo. Barcelona: Hacer Editorial, 2007. 
TARRIUS, A. Pobres en migración, globalización de las economías y debilitamiento de los modelos integradores: el transnacionalismo migratorio en Europa meridional. Empiria. Revista de Metodología de Ciencias Sociales, 2010, № 19, p. 133-156

VALDEBENITO, F. y LUBE-GUIZARDI, M. Espacialidades migrantes. Una etnografía de la experiencia de mujeres peruanas en Arica (Chile). Gazeta de Antropología, 2014, Vol. 31, № 1. Disponible en Internet: http://priem.cl/wp-content/uploads/2015/04/Valdebenito-y-Guizardi_Espacialidades-Migrantes_Una-etnograf--a-de-la-experiencia-de-mujeres-peruanas-en-Arica.pdf

VICUÑA, J.T. y ROJÁS, T. Migración internacional en Arica y Parinacota: Panoramas y tendencias de una región fronteriza. Santiago de Chile: Servicio Jesuita al Migrante, 2015.

WANG, J.; CARLSON, R.; RUSSEL, F.; SIEGAL, H.; RAHMAN, A. \& LI, L. Respondent-driven sampling to recruit MDMA users: a methodological assessment. Drug and Alcohol Dependence, 2005, Vol. 78, No 2, p. 147-157. 
